\title{
Detection and Quantitative Analysis of Two Independent Binding Modes of a Small Ligand Responsible for DC-SIGN Clustering
}

\begin{tabular}{|r|l|}
\hline Journal: & Organic \& Biomolecular Chemistry \\
\hline Manuscript ID & OB-ART-09-2015-002025 \\
\hline Article Type: & Paper \\
\hline Date Submitted by the Author: & $28-$ Sep-2015 \\
\hline Complete List of Authors: & $\begin{array}{l}\text { Nieto, Pedro; CSIC, Glycosystems Lab, Instituto de Investigaciones } \\
\text { Quimicas / cicCartuja ( CSIC / US ) } \\
\text { Guzzi, Cinzia; CSIC, Glycosystems Lab, Instituto de Investigaciones } \\
\text { Quimicas / cicCartuja ( CSIC / US ) } \\
\text { Alfarano, Pietro; University of Milano-Bicocca, Dept Biotechnology and } \\
\text { Biosciences } \\
\text { Sutkeviciute, Ieva; Univ. Grenoble Alpes, Institut de Biologie Structurale } \\
\text { Sattin, Sara; Univ. degli Study di Milano, Dept Chemistry } \\
\text { Ribeiro-Viana, Renato; CSIC, ; CSIC, Glycosystems Lab, Instituto de } \\
\text { Investigaciones Quimicas / cicCartuja ( CSIC / US ) } \\
\text { Fieschi, Franck; Institut de Biologie Strcuturale, } \\
\text { Bernardi, Anna; Universita degli Studi di Milano, Dipartimento di Chimica } \\
\text { Weiser, Joerg; Anterio Consult \& Reseach, } \\
\text { Rojo, Javier; CSIC, } \\
\text { Angulo, Jesus; Instituto de Investigaciones Quimicas ( CSIC - US ), } \\
\text { Department of Bioorganic Chemistry }\end{array}$ \\
\hline
\end{tabular}




\section{Journal Name}

\section{ARTICLE}

\section{Detection and Quantitative Analysis of Two Independent Binding Modes of a Small Ligand Responsible for DC-SIGN Clustering}

Received 00th January 20xx, Accepted 00th January 20xx

DOI: $10.1039 / x 0 x \times 00000 x$

www.rsc.org/

C. Guzzi, ${ }^{a, b}$ P. Alfarano, ${ }^{c}$ I. Sutkeviciute, ${ }^{d, e, f}$ S. Sattin, ${ }^{g}$ R. Ribeiro-Viana, ${ }^{a}$ F. Fieschi, ${ }^{d, e, f}$ A. Bernardi, ${ }^{g}$ J. Weiser, ${ }^{c}$ J. Rojo, ${ }^{a}$ J. Angulo, ${ }^{a, h^{*}}$ and P. M. Nieto ${ }^{a^{*}}$

DC-SIGN (dendritic cell-specific ICAM-3 grabbing non-integrin) is a C-type lectin receptor (CLRs) present, mainly in dendritic cells (DCs), as one of the major pattern recognition receptors (PRRs). This receptor has a relevant role in viral infection processes. Recent approaches aiming to block DC-SIGN have been presented as attractive anti-HIV strategies. DC-SIGN binds mannose or fucose-containing carbohydrates from viral proteins such as the HIV envelope glycoprotein gp120. We have previously demonstrated that multivalent dendrons bearing multiple copies of glycomimetic ligands were able to inhibit DC-SIGN-dependent HIV infection in cervical explant models. Optimization of glycomimetic ligands requires detailed characterization and analysis of their binding modes because they notably influence binding affinities. In a previous study we characterized the binding mode of DC-SIGN with ligand 1, which shows a single binding mode as demonstrated by NMR and X-ray crystallography. In this work we report the binding studies of DC-SIGN with pseudotrisaccharide $\mathbf{2}$, which has a larger affinity. Their binding was analysed by TR-NOESY and STD NMR experiments, combined with the CORCEMA-ST protocol and molecular modelling. These studies demonstrate that in solution the complex cannot be explained by a single binding mode. We describe the ensemble of ligand bound modes that best fit the experimental data and explain the higher inhibition values found for ligand $\mathbf{2}$

\section{Introduction}

Protein-carbohydrate interactions are key in many important biological processes, both physiological and pathological. In particular, these interactions play crucial roles in different aspects of the activation of the immune response, since they are involved in pathogen recognition and in the interactions

\footnotetext{
a. Glycosystems Laboratory. Instituto de Investigaciones Químicas (IIQ) / cicCartuja. CSIC / US, Americo Vespucio, 49, 41092 Sevilla, (Spain). E-mail: pedro.nieto@iiq.csic.es

${ }^{b .}$ Dept. of Biotechnology and Biosciences University of Millano-Bicocca Piazza della Scienza 2 20126, Milan (Italy).

Anterio Consult\&Research GmbH, Augustaanlage 2368165 Mannheim (Germany).

d. Univ. Grenoble Alpes, Institut de Biologie Structurale (IBS), F-38044 Grenoble, (France)

e. CNRS, IBS, F-38044 Grenoble, (France)

f. CEA, IBS, F-38044 Grenoble, (France)

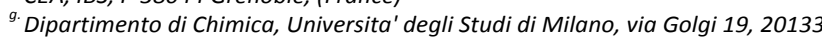
Milano, (Italy)

${ }^{\text {h. }}$ School of Pharmacy, University of East Anglia, Norwich Research Park, Norwich, NR4 TTJ, (UK).

E-mail:j.angulo@uea.ac.uk

Electronic Supplementary Information (ESI) available: [Conformational analysis, models and calculated STD relative to $\omega$ orientation and STD values]. See DOI: $10.1039 / x 0 x \times 00000 x$

CG, JA Perfomed NMR experiments and Corcema-ST calculations; CG, PA and JW designed and performed modelling; IS, SS, RR-V contributed with new and compounds; CG, JA and PMN analysed the data, FF, AB, JW, JR, JA and PMN designed research; Ja and PMN supervise the project, CG, IS, S, FF, AB, JR, JA and PMN wrote the paper.
}

with the cellular host that lead to pathogen neutralization or immune modulation. The key components of these interactions are the animal lectins. ${ }^{1-3} \mathrm{~A}$ large part of animal lectins are members of the C-type or $\mathrm{Ca}^{2+}$-dependent lectin family. ${ }^{4}$ Dendritic cells (DCs) are antigen-presenting cells (APCs), operating at the interface of innate and acquired immunity as they recognize invading pathogens and thereupon activate the adaptive immune response. ${ }^{4}$ DCs express a range of Pathogen-Recognition Receptors (PRRs) including Toll-like receptors (TLRs), NOD-like receptors (NLRs), and C-type lectins receptors (CLRs). DC-SIGN (dendritic cell specific ICAM-3 (intercellular adhesion molecule-3) grabbing non-integrin) is a PRR presents on the surface of the DCs that belong to the type II C-type lectin family. ${ }^{5}$

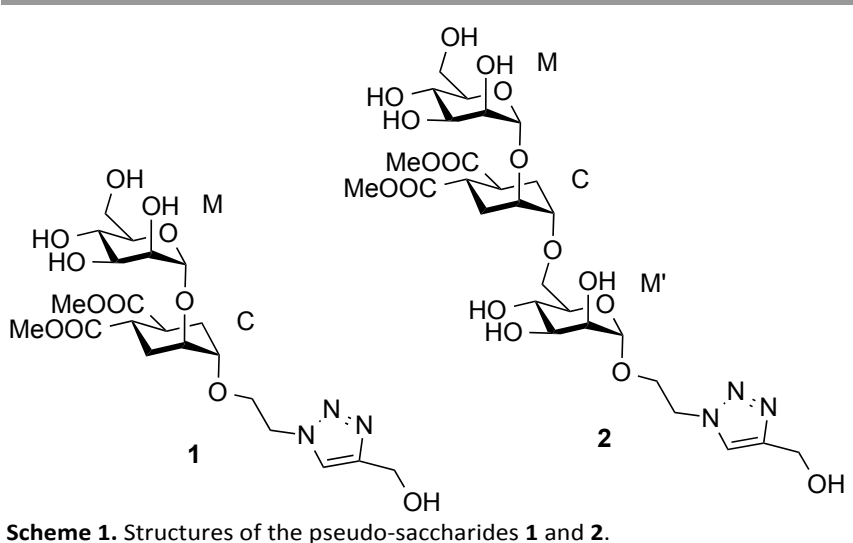


DC-SIGN modulates the outcome of the immune response of DCs by recognition of a broad range of microorganisms, including viruses, bacteria, fungi and parasites. ${ }^{6-13}$ Therefore, it is considered a target for the development of new immunomodulatory and anti-infective therapies. Besides, many studies have revealed DC-SIGN as a promoter of both, cis and trans infection, enabling the escape from host immune responses, such as the case of HIV, Ebola or Hepatitis C virus. 14-17 This highlights the remarkable therapeutic interest in developing DC-SIGN antagonists able to inhibit DC-SIGNpathogen interactions. To improve the affinity and pharmacokinetic properties of natural ligands of DC-SIGN, glycomimetics based on different lead structures have been proposed. $^{18-25}$

Carbohydrate-binding activity of lectins can be ascribed to a limited portion of the protein that is designated as the carbohydrate-recognition domain (CRD). The CRD of DC-SIGN has a globular structure consisting of five $\beta$-strands, two $\alpha$ helices and four disulphide bridges. A loop protrudes from the protein surface and forms part of two $\mathrm{Ca}^{2+}$-binding sites. One of these, known as the principal site, is essential for the direct coordination of the carbohydrate hydroxyl groups. Four amino acids (Glu347 Asn349, Glu354 and Asn365) interacting with the $\mathrm{Ca}^{2+}$ ion form the core of the ligand binding site and rule the specificity of the structures recognized. ${ }^{26-29}$ The CRD, together with the neck region that promotes the lectin's homotetramerization, constitute the extracellular domain (ECD) of DC-SIGN.

DC-SIGN binds mannose or fucose epitopes present in the pathogen's envelope glycoproteins such as gp120 $\left(\mathrm{Man}_{9} \mathrm{GlcNAc}_{2}\right.$ ) or blood group B antigens (Lewis-type). Both structures bind DC-SIGN CRD via $\mathrm{Ca}^{2+}$-mediated interaction in the same binding pocket, named the primary binding site, and with the same $\mathrm{Ca}^{2+}$ atom. ${ }^{26-29}$

We have investigated in detail the interactions of simple oligosaccharides and new glycomimetic ligands bearing mannose or fucose structures with DC-SIGN by NMR spectroscopy combined with computational methods to address the development of further generations of improved glycomimetic ligands. ${ }^{18,21,23,24,30-36}$ These studies have led us to propose that, in solution, mannose- and fucose-containing Lewis ${ }^{X}$ mimics interact within the same binding site with different but simultaneous modes in a multimodal fashion, according to NMR combined with molecular modeling and full matrix relaxation calculations. ${ }^{30,33,35-38}$ A recent analysis using high-resolution multinuclear NMR spectroscopy by Prestegard and coworkers provided the $3 D$ structure of the complex of DC-SIGN with Lewis ${ }^{X}{ }^{39}$ in agreement with our studies on the fucose-containing ligands. ${ }^{21}$

Based on a similar concept, to mimic the natural Mana1-2Man and Mana1-2Mano1-6Man, a pseudo-mannobioside (1) and a pseudo-mannotrioside (2), were synthesized and tested. ${ }^{20,24,40}$ Recently we have fully characterized the binding mode of 1 within the DC-SIGN CRD by a combination of NMR analysis, $X-$ ray crystallography, computational tools and other biophysical methods. ${ }^{24}$ We have demonstrated that it corresponds to a unique well-defined orientation, different from any of the two simultaneous binding modes described for the natural Mana12Man. ${ }^{31}$

The linear pseudo-mannotrioside $\mathbf{2}$ showed an inhibitory potency one order of magnitude higher than $\mathbf{1}$ (IC $\mathrm{C}_{50}$ measured by SPR competition experiments). ${ }^{24}$ However, no explanation for the higher affinity and activity could be inferred from the solid-state structure as no additional contacts were observed in comparison to the pseudo-mannobioside $1 .{ }^{[6 \mathrm{~h}]}$ This affinity difference between $\mathbf{1}$ and $\mathbf{2}$ is lost when the compounds are tethered to multivalent scaffolds and both have similar improved affinity. ${ }^{20}$ On the other hand, data from alternative biophysical techniques such as Isothermal Titration Calorimetry (ITC), Analytical Ultra Centrifugation (AUC), Static Ligth Scattering (SLS), and Dynamic Light Scattering (DLS), indicate the formation of a ternary complex, where $\mathbf{2}$ acts as a bridge capable of clustering two DC-SIGN ECD units (DC-SIGN tetramers) for low ligand-to-protein ratios (2/DC-SIGN ECD ratios between 0.5 and 5). ${ }^{25}$

Since for large ligand-to-protein ratios the binary ligandprotein complex is favoured, we decided to carry out STD $\mathrm{NMR}^{41}$ and transfer NOESY ${ }^{42}$ studies on the binding process of 2 with DC-SIGN ECD in the presence of a large excess of $\mathbf{2}$ (2/DC-SIGN ECD ratio 52:1). Our aim was two-fold: i) to compare that structural information with that obtained from $\mathrm{X}$-ray crystallography in which a single binary protein-ligand complex was observed, and ii) to characterize the binding under more relevant conditions to explain the absence of multivalency effect. ${ }^{25}$

Therefore, herein we provide an analysis of the molecular recognition of mimic 2 by DC-SIGN, using large excess of ligand (52:1) in order to describe at atomic level the binary complex 2/DC-SIGN (ECD) by a combination of NMR experiments in solution and computational techniques (molecular modelling and CORCEMA-ST ${ }^{43}$ ).

\section{Results and Discussion}

The structure of free pseudo-mannotrioside $\mathbf{2}$ was studied by NMR and it was fully consistent with the smaller homologous 1 (see details in the experimental part). ${ }^{25}$ We have performed the NMR studies of the interaction of the pseudomannotrioside with DC-SIGN ECD, using the ligand with an attached triazole moiety at the mannose reducing ring ( $\mathrm{M}^{\prime}$, Scheme 1). The triazole moiety improves the spectral dispersion, while is not affecting the binding nor the threedimensional structure. ${ }^{24}$ The 3D structure of the Mancyclohexyl moiety of $\mathbf{2}$ is consistent with the structure of the common part of 1, while the 1-6 linkage of the mannose at the reducing end has the expected structural features of a 1-6 linkage of a gluco configuration, in equilibrium between gg and gt conformers. The additional dispersion caused by the introduction of the triazole moiety in this case is less pronounced than for the analogous $\mathbf{1}$ and some overlap is observed (Figure 1a). The chemical shifts of the mannose at 
(a)

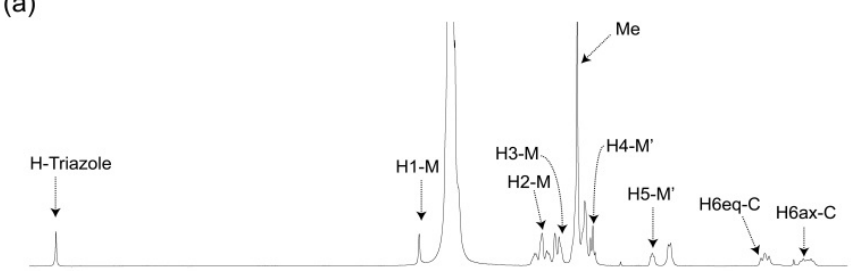

(b)

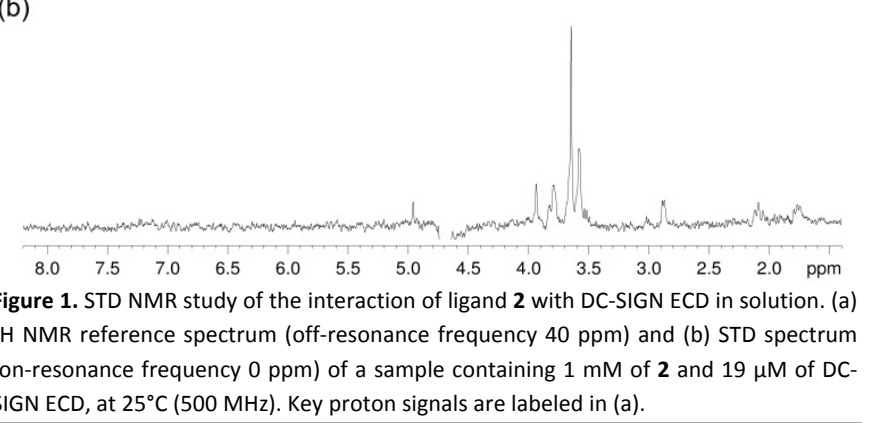

the reducing end $\left(\mathrm{M}^{\prime}\right)$ shift from the normal values towards high field suggesting some shielding effect of the aromatic electronic cloud of the triazole moiety. The NOE values are consistent with an extended conformation with similar structure for the Man - cyclohexyl pseudodisaccharide than 1. ${ }^{44}$ The rest of the molecule exhibits larger flexibility likely to be due to the 1-6 linkage, which has one additional rotatable bond.

In a previous work by us, mimic $\mathbf{2}$ was co-crystallized with monomeric DC-SIGN CRD and the X-ray structure was solved (PDB 2xr6), ${ }^{25}$ providing a valuable structural insight aiding our parallel analysis. X-ray reported a single binding mode of $\mathbf{2}$, with identical orientation of the common part of the molecule as for $\mathbf{1}$, while the reducing mannose in the pseudomannotrioside appeared solvent exposed without new additional contacts observed compared with the pseudomannobioside $\mathbf{1 .}^{25}$ Thus, no explanation for the higher inhibition values for the pseudo-mannotrioside could be deduced from the solid-state structure. Data from other techniques under low ligand-to-protein ratios indicated that 2 could bridge two DC-SIGN ECD units. ${ }^{25}$ Therefore, we have performed STD $\mathrm{NMR}^{41}$ and transfer NOESY ${ }^{45}$ studies of the binding process of $\mathbf{2}$ with DC-SIGN ECD under conditions of large excess of ligand (52:1) to favour the 1:1 complex. The STD NMR experiments of $\mathbf{2}$ in the presence of DC-SIGN ECD clearly indicate binding in solution (Figure 1 and 5). In spite of a significant signal overlap, some key intense STD signals could be accurately integrated, and their growth with saturation time is shown in figure $2 a$. Their intensities reflect short distances to the protein surface in the bound state, and their distribution in relative terms shows the main parts of the ligand contacting the protein, called STD NMR binding epitope (Figure $2 \mathrm{a}$ and $2 \mathrm{c}$ ). ${ }^{46}$

The binding epitope indicates that the non-reducing mannose ring (M) makes additional contacts with the protein, and that the strongest saturation transfer occurs on proton H6ax-C on the cyclohexyl ring of the ligand (Figure 2). This analysis also (a)

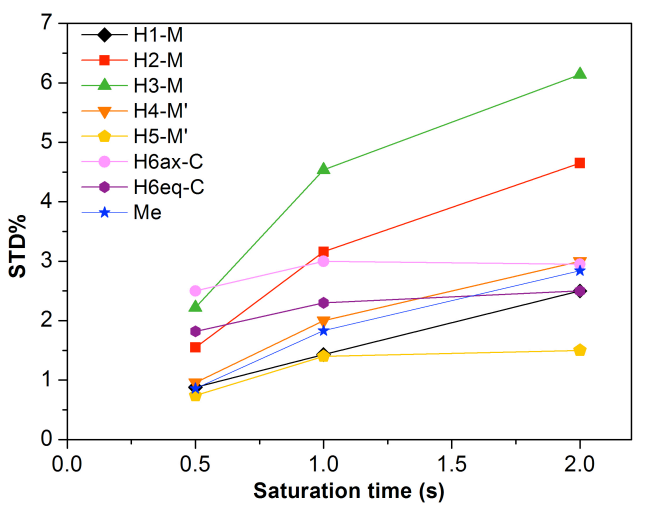

(b)

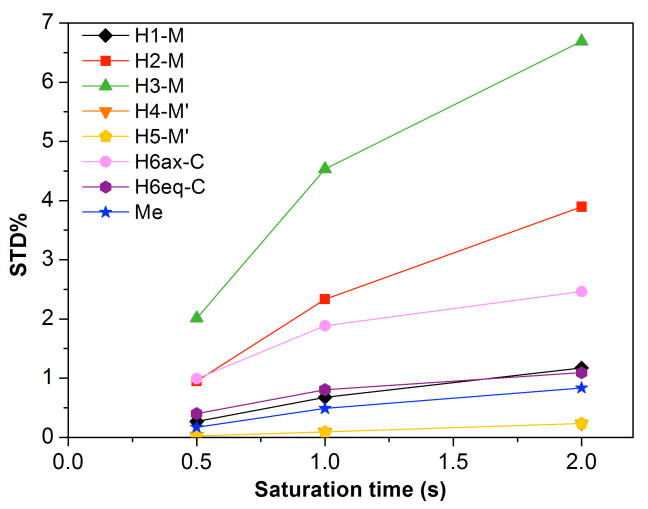

(c)

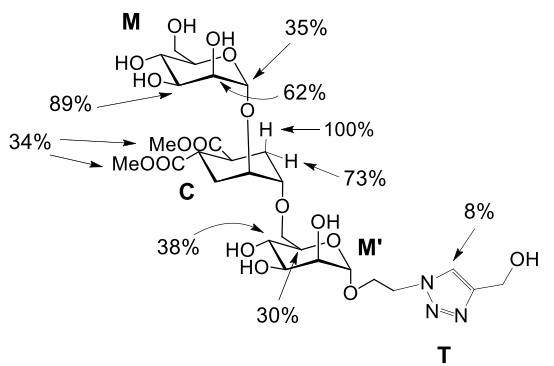

Figure 2. STD NMR curves and ligand epitope map of 2. (a) Experimental STD build-up curves of the binding of $\mathbf{2}$ to DC-SIGN as a function of saturation time (b) Theoretical STD intensities predicted by CORCEMA-ST using the Cartesian coordinates of the X-ray structure. (c) Ligand epitope map of 2 binding to DC-SIGN at $25^{\circ} \mathrm{C}$ showing STD relative values at the shortest saturation time $0.5 \mathrm{~s}$, for non overlapped protons. (See supplementary material)

confirmed that the triazole moiety is not involved in significant protein contacts.

The STD results for the two first residues (non-reducing mannose, $\mathrm{M}$, and cyclohexyl, C) are similar to those obtained for the pseudo-mannobioside 1 constituted by the same residues. ${ }^{[6]]}$ They are compatible with a major bound conformation of pseudo-mannotrioside 2 in a binding mode equivalent to that of $\mathbf{1}$.

This is also in agreement with crystal data, as a superimposition of both $\mathrm{X}$-ray complexes ${ }^{25}$ shows identical bound orientation for the corresponding pseudo-disaccharide moiety, in which the H6ax-C proton is situated close to the methyl groups of Val351, explaining the large saturation received (100\%). In addition to these favourable van der Waals interactions, the non-reducing mannose residue coordinates 


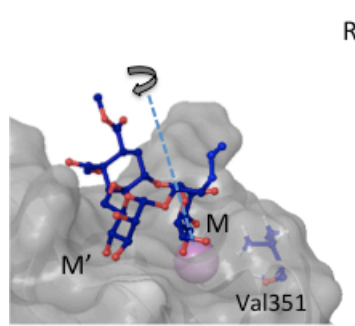

Rotated

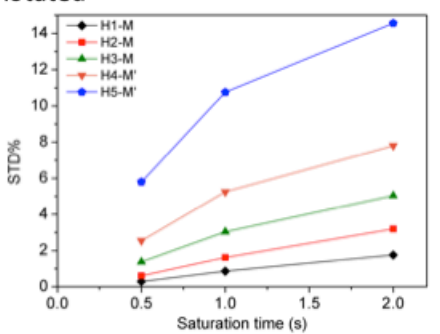

Inverted
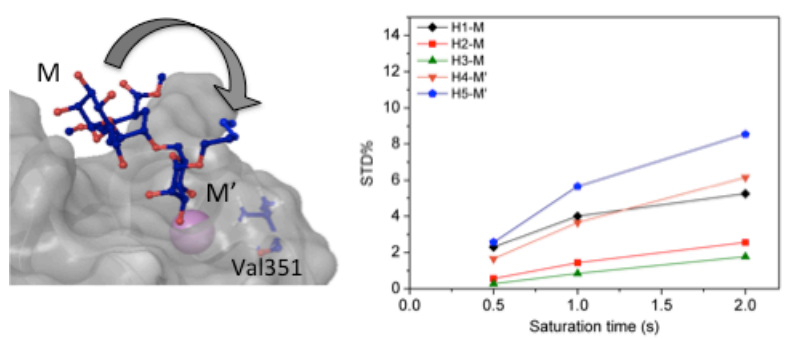

Inverted - Rotated
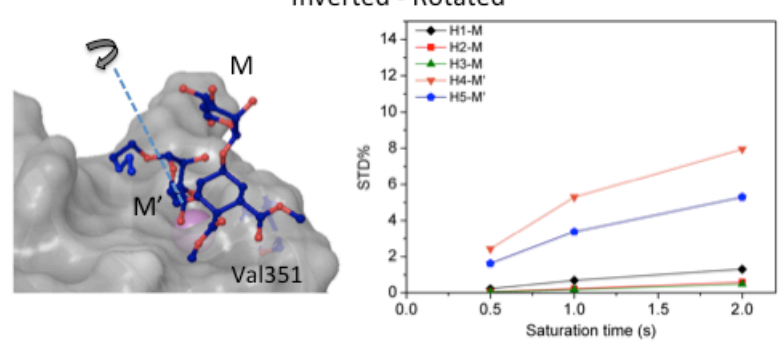

Figure 3. 3D models of the interaction of $\mathbf{2}$ with DC-SIGN obtained by rigid-body rotations and translations of the ligand at the binding site, starting from the crystallographic position, based on a $\mathrm{Ca}^{2+}$ coordination search The corresponding STD intensities predicted for each model by CORCEMA-ST are shown. The theoretical structures were named according to an abbreviated nomenclature as "rotated", "inverted", and "inverted-rotated". Rotated model ( $E=-1920.6 \mathrm{~kJ} / \mathrm{mol}$ ) was obtained by a 180 o rotation around an axis perpendicular to the C3-C4 bond of the non-reducing mannose, resulting an interaction "O4-O3 type" with the $\mathrm{Ca}^{2+}$ atom, rather than "O3O4" (nomenclature by setting Val351 residue on the right of the observer, as a reference). In the "inverted" model ( $E=-1871.2 \mathrm{~kJ} / \mathrm{mol}$ ) the reducing mannose ( $\mathrm{M}$ ') is interacting in the same position as the non-reducing sugar ring $(\mathrm{M})$ in the crystallized pose (03-O4) and in the "inverted-rotated" ( $E=-1894.8 \mathrm{~kJ} / \mathrm{mol}$ ) the coordination of the reducing mannose to $\mathrm{Ca}^{2+}$ is rotated by $180 \circ$ (O4-O3 type). Only those protons signals that could be accurately integrated were plotted.

the $\mathrm{Ca}^{2+}$ ion through its trans-diequatorial hydroxyl groups $\mathrm{M}$ $\mathrm{OH} 3$ and $\mathrm{M}-\mathrm{OH} 4 .^{24,25}$

However, and in contrast to the STD NMR results for 1 that were in complete agreement with the X-ray structure (PDB code 2it6), the observed distribution of saturation transferred to the protons of compound $\mathbf{2}$ did not accurately fit with the structure of the crystallographic complex (PDB code $2 \times r 6$ ). ${ }^{25}$

While in the $X$-ray structure the reducing mannose ring ( $\left.\mathrm{M}^{\prime}\right)$ is solvent exposed, in solution we clearly detect transfer of saturation to $\mathrm{H}_{4}-\mathrm{M}^{\prime}$ and $\mathrm{H} 5-\mathrm{M}^{\prime}$ (Figure 2). This is incompatible with the geometry of the diffraction complex. Moreover, theoretical STD calculations performed with the program CORCEMA-ST ${ }^{43}$ using the X-ray coordinates of the complex did not reproduce the NMR observations. CORCEMA-ST predicts lower intensity for H6ax and H6eq of the cyclohexyl ring (C) and, as expected, close to zero STD values for the reducing mannose residue $\mathrm{H}_{4}-\mathrm{M}^{\prime}$ and $\mathrm{H} 5-\mathrm{M}^{\prime}$ (Figure $2 \mathrm{~b}$ ).

Compounds $\mathbf{1}$ and $\mathbf{2}$, in spite of their structural similarities have different outcome from STD-NMR experiments. We can discard a second low affinity binding site in the protein for $\mathbf{2}$ contributing to the STD effects, under the conditions for STD experiments (large excess of ligand). This circumstance was not detected in the case of $1,{ }^{25}$ so we can exclude the participation of an extra binding site taking place only for ligand $\mathbf{2}$ and not for $\mathbf{1}$, as $\mathbf{2}$ corresponds to the structure of $\mathbf{1}$ with an additional mannose. Consequently, the most likely explanation of the discrepancy between $\mathbf{1}$ and $\mathbf{2}$ STD results is the existence of an additional minor mode of interaction for $\mathbf{2}$ in the same binding site in fast equilibrium with the major one observed in the X-ray complex (PDB code $2 \times r 6$ ) and in solution between DC-SIGN with $1 .{ }^{25}$ Based on earlier works with mannose-based ligands, ${ }^{31}$ potential additional poses of 2 contributing to the STD signals via the reducing end mannose interacting into the same binding site could be at the origin of this observation. This situation where the fast equilibrium between several binding modes into the same binding site is revealed by distortions of the binding epitope, as this case, has been already described for this particular protein. ${ }^{21,23,31}$

Our first attempt to explain the NMR data in solution was to consider that the larger flexibility of the 1-6 linkage might be at the origin of the discrepancy, as several conformations could interact with DC-SIGN CRD. We built additional models based on a $1 \rightarrow 6$ torsional search. Starting from the X-ray structure, (PDB code $2 \times r 6$ ), the dihedral angles $\psi$ and $\omega$ were varied to generate an ensemble of all the potential conformers. Complexes with DC-SIGN were constructed and superimposed onto the positions of the common pseudodisaccharide ( $\mathrm{M}$ and $C$ residues, Scheme 1). They were further energy minimized and those with severe steric clashes into the complex were discarded.

The resulting models (A, B, C, and D see supplementary material Figures S1-S4) presented distances in agreement with NOE data. Nevertheless, the $\mathrm{H} 4$ and $\mathrm{H} 5$ protons of the reducing mannose $\left(\mathrm{M}^{\prime}\right)$ remained solvent exposed and we did not appreciate any significant effect on their STD theoretical intensities upon changes in 1-6 torsion angles. In general, the theoretical STD build-up curves obtained from CORCEMA-ST calculations using the coordinates of these molecular models were practically equivalent to each other and very similar to those of the crystallographic complex (see supplementary material). Thus, all the attempts to explain the STD NMR results based on variations of the 1-6 linkage were unsuccessful.

Then, we considered additional potential models of interaction based on the $\mathrm{Ca}^{2+}$ coordination of two hydroxyl groups of the ligand within the DC-SIGN binding site (Figure 3). We applied rigid-body rotations and translations to the ligand starting from the crystallographic position, conserving the $\mathrm{OH}-3$ and $\mathrm{OH}-4 \mathrm{Ca}^{2+}$ coordination. 
Table 1 NOE R-Factor as function of the proportional weight of the X-ray structure vs the inverted-rotated mode

\begin{tabular}{ccc} 
X-ray & Inverted-Rotated & R-Factor \\
\hline 100 & 0 & 0.46 \\
80 & 20 & 0.22 \\
60 & 40 & 0.26 \\
40 & 60 & 0.51 \\
20 & 80 & 0.79 \\
0 & 100 & 1.08
\end{tabular}

Three operations were considered: swapping between $\mathrm{OH}-3$ and $\mathrm{OH}-4$ positions (rotations), changing the coordinating mannose residue (inversion), and the combination of both (inversion-rotation). ${ }^{21,31}$ The obtained structures were named according to an abbreviated nomenclature relative to the X-ray complex (Figure 3 and Experimental Section). The CORCEMAST STD values for each individual mode of interaction were incompatible with the experimental STD NMR results, meaning that a single 3D molecular binding form was not able to fully explain the NMR data in solution.

Thus, we decided to carry out an analysis of the STD NMR observations assuming that two different binding modes, within the same site, contribute to the final intensities. In this way, the total saturation observed in the STD experiment would be the weighted average of the accumulated saturations corresponding to each binding mode. In this quantitative analysis, we only considered those signals that could be accurately integrated. ${ }^{33}$ We used the initial slope approach $\left(\mathrm{STD}_{0}\right)$ to study this bimodal system in order to ensure that the individual STD values are not affected by crossrebinding processes during the saturation time that would mix the STD information in a very complex way. ${ }^{37}$

$$
\mathrm{P}+\mathrm{L} \rightleftharpoons \mathrm{PL}_{1}+\mathrm{PL}_{2}
$$

Following the initial slope approach, the $\mathrm{STD}_{0}$ of the ensemble can be estimated by the addition of the $\mathrm{STD}_{0}$ contributions from the individual components.

For this multimodal binding analysis of the STD data only those protons that could be accurately integrated were considered avoiding uncertain contributions in the case of overlapped signals. Unfortunately, signal $\mathrm{H} 6 \mathrm{eq}-\mathrm{C}$, which has the strongest STD effect, did not have enough dispersion to be quantified. The theoretical bimodal binding equilibrium was considered in all cases as pair-wise combinations of the X-ray structure with any of the other three molecular models of the complexes (Figure 4 and Table 1). The NOE R-factor indicated the quality of the prediction. We found that a reasonable theoretical experimental agreement (NOE R-factor $=0.2)^{47,48}$ could be reached by considering the equilibrium of the following two bound conformations in solution: the major one ( $\sim 80 \%)$ from the X-ray structure and a minor contribution ( 20\%) from the complex as arranged in the "inverted-rotated" model (Table 1 ). However, the major binding mode is still compatible with a mixture of different conformers (Figure 4 bottom left, supplementary material figures S1-S4). The absence of key
Experimental
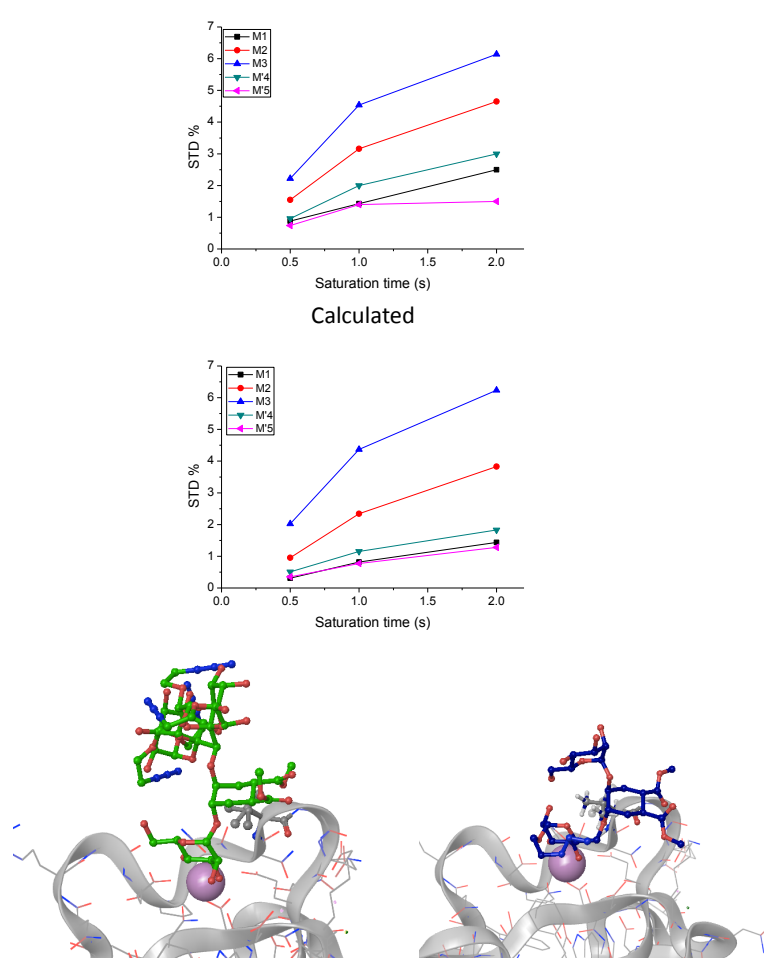

Figure 4. Combination of the binding modes of pseudo-mannotrioside with DCSIGN receptor that have shown the best fit with the experimental STD NMR intensities and considering a bimodal system (top). The lowest NOE R-factor, as well as the simple comparison of the experimental and predicted STD growth curves, proves that a major contribution $(\sim 80 \%)$ of the X-ray complex represented by a superimposition of the $\omega$ rotamers $A, B, C$, and $D$ (bottom left) combined with a minor one from the "inverted-rotated" model ( 20\%) (bottom right), would explain the experimental STD NMR outcomes in solution.

NOE cross peaks (Figure 5) did not allow determining the conformation around the cyclohexyl $1 \rightarrow 6$ mannose linkage, very likely due to an increased flexibility at that region of the molecule. $^{49}$ We carried out NOESY experiments ${ }^{45}$, 50 on pseudo-mannotrioside 2 both free and in the presence of DCSIGN. Analysis of the spectra (Figure 5) led us to the conclusion that there are no important conformational changes in the ligand upon binding to DC-SIGN. Only irrelevant differences in the NOE pattern are attributable to protein mediated spin diffusion. ${ }^{51,52}$

The conformation-defining key NOEs that could be unambiguously detected (highlighted by a square in figure 5) are either present $(\mathrm{H} 1-\mathrm{M} / \mathrm{H} 3$ eq- $\mathrm{C})$ or absent $\left(\mathrm{H} 5-\mathrm{M}^{\prime} / \mathrm{H} 6 \mathrm{eq}-\mathrm{C}\right)$ equally in both spectra, indicating the same conformation in the free and bound states. As in the STD NMR study, the transfer NOESY data did not fully agree with the X-ray complex. In the crystal structure, the conformation around the 1,6 linkage between the cyclohexyl (C) and the reducing 

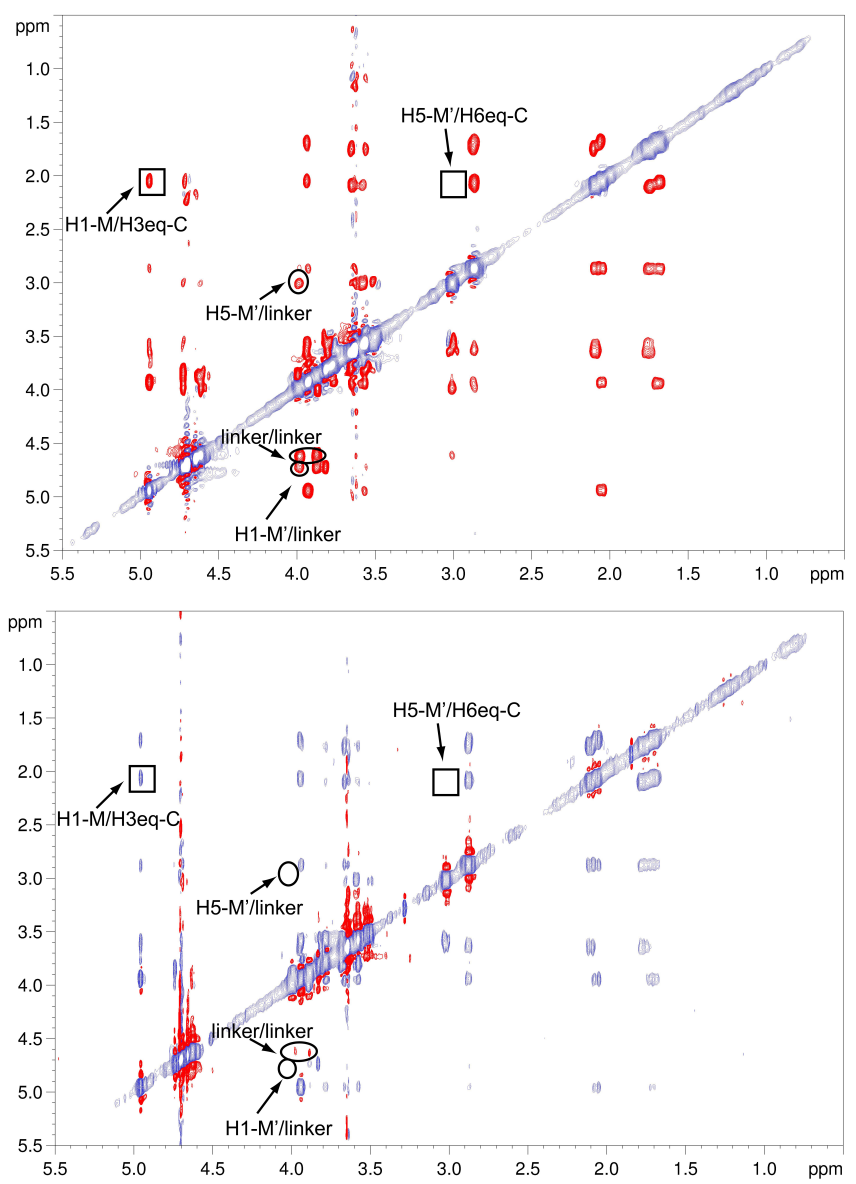

Figure 5. Comparison of NOESY spectra (25ㅇ, $500 \mathrm{MHz}$ ) of ligand 2, (top) free ( $2.3 \mathrm{mM}$, mixing time $500 \mathrm{~ms}$ ), and (bottom) bound to DC-SIGN (1 mM, $19 \mu \mathrm{M}$ protein, mixing time $300 \mathrm{~ms}$ ). The conformation-defining key NOEs (highlighted by a square) are either present (H1-M/H3eq-C) or absent (H5-M'-H6eq-C) equally in both spectra, indicating the same conformation in the free and bound states. Cross peaks not observed in the bound state, indicative of high flexibility of the reducing end in the protein-ligand complex, are surrounded by a circle.

mannose ring ( $\mathrm{M}^{\prime}$ ) should lead to a strong $\mathrm{H} 5-\mathrm{M}^{\prime} / \mathrm{H} 6 \mathrm{eq}-\mathrm{C} \mathrm{NOE}$, which was not observable in any of the spectra (Figure 5). However, we observed a strong $\mathrm{H} 1-\mathrm{M} / \mathrm{H} 3$ eq-C NOE, characteristic to the extended conformation around the 1,2 linkage of the mannose-cyclohexyl moiety of the pseudotrisaccharide, compatible with the X-ray structure, ${ }^{44}$ and similar to the previously studied pseudo-mannobioside $1 .^{24}$

\section{Results and Discussion}

\section{Synthetic procedures.}

Thin layer chromatography (TLC) analyses were performed on silica gel $60 \mathrm{~F}_{254}$ precoated on aluminium plates (Merck) and the compounds were detected by staining with sulfuric acid/ethanol (1:9), with cerium (IV) sulfate (10 g)/phosphomolybdic acid (13 g)/sulfuric acid (60 mL) solution in water $(1 \mathrm{~L})$, or with anisaldehyde solution [anisaldehyde (25 $\mathrm{mL}$ ) with sulfuric acid $(25 \mathrm{~mL})$, ethanol $(450 \mathrm{~mL})$ and acetic acid $(1 \mathrm{~mL})$ ], followed by heating at over $200^{\circ} \mathrm{C}$. Column chromatography was carried out on silica gel $60(0.2-0.5 \mathrm{~mm}$, 0.2-0.063 mm or 0.040-0.015 mm; Merck). ${ }^{1} \mathrm{H}$ - and ${ }^{13} \mathrm{C}-\mathrm{NMR}$ spectra were acquired on Bruker DPX-300, Avance III-400 and DRX-500 spectrometers. Unit A refers to the reducing end monosaccharide in the NMR data. Electrospray mass spectra (ESI MS) were carried out with an Esquire 6000 ESI-Ion Trap from Bruker Daltonics.

Synthesis of compound 2. Pseudo-mannotrioside $2^{20}(20 \mathrm{mg}, 0.03$ $\mathrm{mmol})$, propargyl alcohol $(10 \mu \mathrm{L}, 0.02 \mathrm{mmol}), \mathrm{CuSO}_{4} .5 \mathrm{H}_{2} \mathrm{O}(0.8 \mathrm{mg}$, $0.003 \mathrm{mmol}$ ), sodium ascorbate $(1.3 \mathrm{mg}, 0.006 \mathrm{mmol}$ ) and TBTA (3.4 $\mathrm{mg}, 0.006 \mathrm{mmol}$ ) were dissolved in $1 \mathrm{~mL}$ of THF/ $\mathrm{H}_{2} \mathrm{O}(1: 1)$. After 1.5 $\mathrm{h}$, the solvent was evaporated and the resulting crude was purified by flash chromatography in silica $\left(\mathrm{CH}_{2} \mathrm{Cl}_{2} / \mathrm{MeOH}\right.$ 9:1, 8:2.5, 7:3), furnishing $17 \mathrm{mg}$ ( $81 \%$ yield) of compound 2 as oil. ${ }^{1} \mathrm{H}$ NMR $\left(\mathrm{D}_{2} \mathrm{O}\right.$, $500 \mathrm{MHz}$ ): $\delta 8.04$ (s, 1H, Htriazol), 5.03 (bs, $1 \mathrm{H}, \mathrm{H}-1$ mann'), 4.81 (bs, $1 \mathrm{H}, \mathrm{H}-1$ mann), $4.73\left(\mathrm{~s}, 2 \mathrm{H}, \mathrm{CtriazolCH} \mathrm{H}_{2} \mathrm{OH}\right)$, 4.71-4.68 $\left(\mathrm{m}, 2 \mathrm{H}, \mathrm{CH}_{2} \mathrm{~N}\right)$, 4.10-4.05 $\left(\mathrm{m}, 1 \mathrm{H}, \mathrm{OCH}_{2} \mathrm{CH}_{2} \mathrm{~N}\right)$, 4.04-3.99 (m, 2H, H-2mann', O6mannCHCHO), 3.98-3.94 (m, $\left.1 \mathrm{H}, \mathrm{OCH}_{2} \mathrm{CH}_{2} \mathrm{~N}\right), 3.92-3.89(\mathrm{~m}, 2 \mathrm{H}$, H-2mann, H-6mann'), 3.88-3.83 (m, $1 \mathrm{H}, \mathrm{H}-3$ mann $\left.^{\prime}\right)$, 3.76-3.70 (m, 9H, H-6mann', H-6mann, O6mannCHCHO, $\left.\mathrm{CH}_{3}\right), 3.69-3.63(\mathrm{~m}, 4 \mathrm{H}$, H-6mann, H-3mann, H-4mann', H-5mann'), 3.58 (at, J = 9.5 Hz, 1H, H-4mann), 3.12-3.07 (m, 1H, H-5mann), 2.97-2.93 (m, 2H, $\left.\mathrm{CHCOOCH}_{3}\right), 2.20-2.11(\mathrm{~m}, 2 \mathrm{H}, \mathrm{OCHCHeqHax}), 1.87-1.74(\mathrm{~m}, 2 \mathrm{H}$,

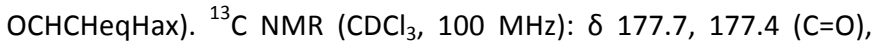
146.9 (Ctriazol), 124.5 (CHtriazol), 99.6 (C-1mann), 98.4 (C-1mann'), 74.3 (C-1CH), 73.3 (C-4mann"), 71.7 (C-5mann), 70.8 (C-3mann), 70.4 (C-2mann', C-2CH), 69.7 (C-2mann), 69.5 (C-3mann'), 66.7 (C5 mann'), 66.5 (C-4mann), $65.7\left(\mathrm{OCH}_{2} \mathrm{CH}_{2} \mathrm{~N}\right), 60.9$ (C-6), 54.5 (CtriazolCH $\left.\mathrm{CH}_{2} \mathrm{OH}\right), 52.5\left(\mathrm{CH}_{3}\right), 49.9\left(\mathrm{OCH}_{2} \mathrm{CH}_{2} \mathrm{~N}\right), 38.9(\mathrm{C}-4 \mathrm{CH}, \mathrm{C}-5 \mathrm{CH})$, 26.8 (C-6CH), 26.5 (C-3CH) ESI-MS calc. for $\mathrm{C}_{27} \mathrm{H}_{43} \mathrm{~N}_{3} \mathrm{O}_{17}$ (m/z): 681.3; found: $704.3\left[\mathrm{M}^{+} \mathrm{Na}\right]$.

\section{NMR spectroscopy experiments}

NMR spectroscopy experiments were performed on a Bruker Avance DRX $500 \mathrm{MHz}$ spectrometer equipped with a $5 \mathrm{~mm}$ inverse triple-resonance probe head, at 25 으. The samples were prepared at $2.3 \mathrm{mM}$ in $550 \mu \mathrm{L}$ of $99.9 \% \mathrm{D}_{2} \mathrm{O}$ for complete assignment of the ligand signals and at $1 \mathrm{mM}$, in buffer $\mathrm{D}_{2} \mathrm{O}$ (150 mM NaCl, $4 \mathrm{mM} \mathrm{CaCl}_{2}, 25 \mathrm{mM}$ Tris-d11, pD 8) for the experiments in the presence of the receptor (DC-SIGN ECD 19 $\mu M)$. The same sample was used for both, STD NMR and transfer NOESY experiments. NOESY experiments were carried out using a phase sensitive pulse program with gradient pulses in the mixing time and with presaturation ${ }^{53}$ Mixing times of 150, 300, and $500 \mathrm{~ms}$ were used for TR-NOESY spectra and 500 ms for NOESY spectra. 
STD NMR experiments were registered with $3 \mathrm{~K}$ scans by using a train of Gaussian shaped pulses of $49 \mathrm{~ms}$ (field strength of ca. $80 \mathrm{~Hz}$ ), an inter-pulse delay of $1 \mathrm{~ms}$ and $15 \mathrm{~ms}$ spin-lock pulse (field strength of $3.7 \mathrm{kHz}$ ) prior acquisition. The on-resonance frequency was set to $0 \mathrm{ppm}$ while the off-resonance frequency was $40 \mathrm{ppm}$. Appropriate blank experiment was performed to assure the lack of direct saturation of the ligand protons. Saturation times of $0.5,1$ and $2 \mathrm{~s}$ were used to obtain the STD build-up curves and, in each experiment, the recovery delay

$$
S T D_{0}(\text { dual binding })=\left.\frac{\left(I_{0}-I_{\text {sat }}^{1}\right)+\left(I_{0}-I_{\text {sat }}^{2}\right)}{I_{0}}\right|_{t s a t \rightarrow 0}=S T D_{0}^{1}+S T D_{0}^{2}
$$

(d1) was inversely varied relative to the saturation time, in order to maintain constant the total time of the experiment.

The experimental STD growth curve $\left(I_{0}-I_{\text {sat }} / I_{0}\right)$ of H6ax proton of cyclohexane ring could not be fitted to an exponential function (equation: STD $\left(t_{\text {sat }}\right)=$ STD $_{\max }$ (1- e $\left.\mathrm{k}_{\text {sat }} \cdot \mathrm{t}_{\text {sat }}\right)$ ), due to its fast relaxation. Therefore, instead of using the analysis of initial slopes of the STD intensities, ${ }^{54}$ the binding epitope was characterized by using the shortest saturation time $(0.5 \mathrm{~s})$ to avoid artefacts due to differential relaxation properties. The ligand epitope map was then obtained by normalization of the whole set of the STD intensities at $0.5 \mathrm{~s}$ against the highest STD value (proton $\mathrm{H} 6 \mathrm{ax}$ of cyclohexane ring as a reference), and expressing the result in percentage.

\section{CORCEMA-ST}

The Cartesian co-ordinates of the crystal structure of the complex DC-SIGN CRD/pseudotrisaccharide 2 (pdb code $2 \times r 6$ ) were used for the full relaxation matrix calculations. In order to explain the NMR data in solution, starting from the X-ray complex, further models of the interaction were built (see above), and their Cartesian coordinates used for the full relaxation matrix calculations.

As no chemical shift assignment of the protein protons was available, they were predicted by using the program ShiftX 1.1 (http://shiftx.wishartlab.com). Although the experimental irradiation frequency for selective saturation was established at $0 \mathrm{ppm}$, all the protein protons with chemical shifts predicted to be within the $[0.7,-0.7] \mathrm{ppm}$ range were included, as ShiftX ${ }^{55}$ does not consider the effects of line broadening under the experimental conditions. All exchangeable hydrogen atoms were excluded in the calculations, as the STD NMR experiments were performed in $\mathrm{D}_{2} \mathrm{O}$. Identical PDB coordinates for the bound and free protein were assumed and to reduce the dimensions of the matrices, a cut off of $8 \AA$ from the ligand was used. Assuming a spherical shape for the protein tetramer, the correlation time of bound ligand was set to 115 ns whereas 0.5 ns was used for the free ligand, and 10 ps for the internal correlation time of methyl groups. ${ }^{43}$ For this protein-ligand system, the classical assumption of an association step limited by diffusion (on-rate $10^{8} \mathrm{M}^{-1} \mathrm{~s}^{-1}$ ) was considered. The experimentally determined $K_{D}$ value pseudo- trimannoside was used $(5 \mu \mathrm{M})$ and the resulting off-rate was $500 \mathrm{~Hz}$.

The theoretical STD intensities for each binding mode were calculated as percentage fractional intensity changes $\left(\mathrm{S}_{\mathrm{calc}, \mathrm{k}}=\right.$ $\left(\left(\left[\left(I_{0 k}-I(t)_{k}\right) \cdot 100\right] / I_{0 k}\right)\right.$, were $k$ is a particular proton in the complex, and $\mathrm{I}_{0 \mathrm{k}}$ its thermal equilibrium value from the intensity matrix $\mathrm{l}(\mathrm{t})$, and the calculation was carried out for the whole set of saturation times experimentally measured. From the resulting STD build-up curves, a mathematical fitting to a mono-exponential equation $\left(S T D\left(t_{\text {sat }}\right)=S T D_{\max }\left(1-\exp \left(-k_{\text {sat }} t_{\text {sat }}\right.\right.\right.$ )) was done, and the initial slope $\mathrm{STD}_{0, \text { calc }}$ was obtained.

For the study of the bimodal system using the initial slope approach:

$$
S T D_{0}(\text { dual binding })=\left.\frac{\left(I_{0}-I_{\text {sat }}^{1}\right)+\left(I_{0}-I_{\text {sat }}^{2}\right)}{I_{0}}\right|_{t s a t \rightarrow 0}=S T D_{0}^{1}+S T D_{0}^{2}
$$

The $\mathrm{STD}_{0 \mathrm{i}}$ contribution from each " $\mathrm{i}$-th" binding mode will be proportional to the concentration of the complex in the sample $\left(\left[\mathrm{PL}_{\mathrm{i}}\right]\right.$; in this case, $\left[\mathrm{PL}_{1}\right]$ or $\left.\left[\mathrm{PL}_{2}\right]\right)$, which will be determined by its corresponding affinity $\left(K_{D 1}\right.$ or $\left.K_{D 2}\right)$. Nevertheless, for this protein-ligand system, the available data was the dissociation constant from ITC measurements $\left(K_{D}=5\right.$ $\mu \mathrm{M}) .{ }^{25}$ In this measurement, the global affinity of the DC-SIGN lectin for $\mathbf{2}$ was obtained, so no information on the individual affinities of the potential different binding modes was available. We then considered the final dissociation constant from ITC as a weighted average of the different affinities of each binding mode, and, as an approximation, calculated each theoretical STD contribution using that value. By doing so, the weighting of each complex must be done then by introducing a population factor for every contributing complex $\left(f_{1}\right.$ and $f_{2}$, for $\mathrm{PL}_{1}$ and $\mathrm{PL}_{2}$, respectively, and $f_{1}+f_{2}=1$ ):

$$
S T D_{0}^{O B S}=f_{1} \cdot S T D_{0}^{1}+f_{2} \cdot S T D_{0}^{2}
$$

For this multimodal binding analysis of the STD data only those protons that could be accurately integrated were used, avoiding uncertain contributions in the case of overlapped signals. The theoretical bimodal binding equilibrium was considered in all cases as pair-wise combinations of the X-ray structure with any one of the other three molecular models of the complexes. (Fig. 5), and the goodness of the prediction was measured by the NOE R-factor.

The theoretical STD values were compared to experimental ones using the NOE R-factor defined as:

$$
\sqrt{\frac{\sum W_{k}\left(S T D_{0, k}^{\exp }-S T D_{0, k}^{\text {calc }}\right)^{2}}{\sum W_{k}\left(S T D_{0, k}^{\text {exp }}\right)^{2}}}
$$

where $S T D_{0, k}^{\exp }$ and $S T D^{\text {calc }}{ }_{0, k}$ are the experimental and calculated STD intensities, respectively, of proton $\mathrm{k}$. A lower NOE R-factor indicates better fit between experimental and 
theoretical data and, thus, better appropriateness of the chosen structural model of the complex.

\section{Molecular modelling:}

Protein setup: By starting from the crystal structure (resolution=1.55 $\AA$ ) of human DC-SIGN in a complex with $\mathrm{Man}_{4}$ (PDB code 1s/4), ${ }^{29}$ a molecular model of the protein was constructed. By using the Protein Preparation Wizard within the Maestro graphical interface, ${ }^{56}$ the crystal structure was modified by deleting all crystal waters, assigning bond orders and adding hydrogen atoms. Protonation states of basic and acidic residues were assigned by optimization of the hydrogenbonding network. A minimization was carried out on the final protein structure by using the OPLS2005 force field. ${ }^{57}$

Ligand conformational search: Models A, B, C, and D (based on $1 \rightarrow 6$ torsional search, were prepared by varying the dihedral angles $\Psi$ and $\omega$ according to the most stable values (conformers gg gt and $\mathrm{tg}$ ) followed by a minimization by using the OPLS2005 force field.

Docking: The theoretical structures, named according to an abbreviated nomenclature, "rotated", "inverted", and "inverted-rotated", were obtained by rigid rotations and translations of the ligand $\mathbf{2}$ within the DC-SIGN binding site, starting from the crystallographic position, based on a $\mathrm{Ca}^{2+}$ coordination search. All complexes were further minimized by using the OPLS2005 force field, ${ }^{56}$ an implicit water model ${ }^{58,59}$ with constant dielectric, and with the van der Waals, electrostatic and hydrogen bond cutoffs set to 8,20 , and 4, respectively. Some rotamers were slightly moved to avoid steric problems and the final models correspond to the lowest energy structures arising from conformational searches by using a mixed torsional/low-mode sampling method. ${ }^{60}$ The "rotated" model $(\mathrm{E}=-1920.6 \mathrm{~kJ} / \mathrm{mol})$ was obtained by a 180 응 rotation around an axis perpendicular to the C3-C4 bond of the non-reducing mannose, resulting an interaction "O4-O3 type" with the $\mathrm{Ca}^{2+}$ atom, rather than "O3-O4" (in this nomenclature, the Val351 residue is always set on the right of the observer, as a reference). In the "inverted" model $(E=-1871.2 \mathrm{~kJ} / \mathrm{mol}$ ) the reducing mannose $\left(\mathrm{M}^{\prime}\right)$ is interacting in the same position of the non-reducing sugar ring $(\mathrm{M})$, as in the crystallized pose (O3-O4) and, in the "inverted-rotated" ( $\mathrm{E}=-1894.8 \mathrm{~kJ} / \mathrm{mol}$ ) the coordination of the reducing mannose to $\mathrm{Ca}^{2+}$ is rotated by 180 (O4-O3 type).

\section{Conclusions}

The analysis of the combined NMR data (STD-NMR and transfer NOESY) indicates that at high ligand to protein ratio $(52: 1)$ the pseudo-mannotrioside ligand 2 binds to DC-SIGN in a binary but multimodal fashion involving both mannose ends, yielding two complexes with similar but asynchronous interactions with the same $\mathrm{Ca}^{2+}$ atom. The main binding mode is similar to that from the $X$-ray structure but with participation of additional conformers regarding the flexible 16 linkage.
The involvement of both mannose residues of $\mathbf{2}$ in the binding to DC-SIGN is compatible with the outcomes from other biophysical techniques (AUC, SLS and DLS) ${ }^{25}$ At lower ligand to protein ratio (5:1), the two mannose units of 2 cause clustering of DC-SIGN ECD by concurrent interactions of both residues with two protein tetramers explaining the stronger binding observed for $\mathbf{2}$ compared with the pseudo-disaccharide $\mathbf{1}$, as we previously reported. ${ }^{61}$ In addition, this model also explains the reduction of the affinity difference between the two ligands when they were tethered into multivalent systems attached from their reducing ends, because this prevents the second mannose unit of $\mathbf{2}$ from being involved in binding. ${ }^{25}$

In this work, as the NMR experiments have been registered with a very large excess of ligand (52:1 molar ratio) we can ensure that no species other than 1:1 are observed by STDNMR nor transfer NOESY. ${ }^{25}$ Our results can be explained by the existence of multiple binding modes of carbohydrate-based ligands upon interaction with DC-SIGN as it has been previously reported. ${ }^{18-29}$ STD NMR has proven to be very sensitive to the existence of minor binding modes with alternative orientations of the ligand within the same binding site, ${ }^{18,21,23,30-38}$ and it avoids the possible loss of crucial structural information resulting from the individual detection of the major complex. We believe that this alternative mode should be present in the ternary complex between DC-SIGN tetramers and the glycomimetic $\mathbf{2}$ recently reported by some of us. ${ }^{25}$ Therefore we suggest that the STD NMR approach for the detection of bimodal binding involving other orientations of the ligand can predict dimerization of protein by ligand bridging interactions.

Herein, we provide not only a complete description of the DCSIGN recognition process of glycomimetic 2 , but we propose that STD NMR observation of bimodal binding involving inverted orientations of the ligand can be used as a predictor of protein dimer formation by ligand bridging interactions. In this way, STD NMR studies can avoid misinterpretation of affinity data under low ligand/protein ratio conditions in these particular systems. In addition, this work highlights how a multidisciplinary approach combining different experimental methods with theoretical ones, probably is the most appropriate strategy for deeper structural characterization of weak protein-carbohydrates interactions. ${ }^{62}$

\section{Acknowledgements}

This work was supported by Spanish Ministry of Science and Innovation (CTQ2009-07168, CTQ2011-23410, CTQ201232605; and RYC-2007-01791 to J.A.), and the EU, FEDER. We thank EU ITN Marie-Curie -program (CARMUSYS - Grant number 213592) for funding C.G., P.A., I.S. and R.R. F.F. thanks for financial support by the Institut Universitaire de France

\section{Notes and references}

1. D. C. Kilpatrick, Biochim. Biophys. Acta, 2002, 1572, 187-197.

2. H. J. Gabius, H. C. Siebert, S. Andre, J. Jimenez-Barbero and H. Rudiger, ChemBioChem, 2004, 5, 740-764. 
3. G. R. Vasta, Nat. Rev. Microbiol., 2009, 7, 424-438.

4. J. Banchereau and R. M. Steinman, Nature, 1998, 392, 245-252.

5. Y. van Kooyk and T. B. Geijtenbeek, Nat. Rev. Immunol., 2003, 3, 697-709.

6. F. Baribaud, S. Pohlmann and R. W. Doms, Virology, 2001, 286, 1-6.

7. F. Halary, A. Amara, H. Lortat-Jacob, M. Messerle, T. Delaunay, C. Houles, F. Fieschi, F. Arenzana-Seisdedos, J. F. Moreau and J. Dechanet-Merville, Immunity, 2002, 17, 653-664.

8. C. P. Alvarez, F. Lasala, J. Carrillo, O. Muñiz, A. L. Corbí and R. Delgado, J. Virol., 2002, 76, 6841-6844.

9. E. Navarro-Sanchez, R. Altmeyer, A. Amara, O. Schwartz, F. Fieschi, J. L. Virelizier, F. Arenzana-Seisdedos and P. Desprès, EMBO Rep., 2003, 4, 723-728.

10. A. Cambi, K. Gijzen, I. J. M. de Vries, R. Torensma, B. Joosten, G. J. Adema, M. G. Netea, B. J. Kullberg, L. Romani and C. G. Figdor, Eur. J. Immunol., 2003, 33, 532-538.

11. I. van Die, S. J. van Vliet, A. K. Nyame, R. D. Cummings, C. M. C. Bank, B. Appelmelk, T. B. H. Geijtenbeek and Y. van Kooyk, Glycobiology, 2003, 13, 471-478.

12. A. Marzi, T. Gramberg, G. Simmons, P. Moller, A. J. Rennekamp, M. Krumbiegel, M. Geier, J. Eisemann, N. Turza, B. Saunier, A. Steinkasserer, S. Becker, P. Bates, H. Hofmann and S. Pohlmann, J. Virol., 2004, 78, 12090-12095.

13. W. E. Paul, Cell, 2011, 147, 1212-1215.

14. S. Pohlmann, F. Baribaud and R. W. Doms, Trends Immunol., 2001, 22, 643-646.

15. Y. van Kooyk, B. Appelmelk and T. B. Geijtenbeek, Trends Mol. Med., 2003, 9, 153-159.

16. P. Y. Lozach, H. Lortat-Jacob, A. De Lacroix de Lavalette, I. Staropoli, S. Foung, A. Amara, C. Houlès, F. Fieschi, O. Schwartz, J. L. Virelizier, F. Arenzana-Seisdedos and R. Altmeyer, J. Biol. Chem., 2003, 278, 20358-20366.

17. P.-Y. Lozach, A. Amara, B. Bartosch, J.-L. Virelizier, F. ArenzanaSeisdedos, F.-L. Cosset and R. Altmeyer, J. Biol. Chem., 2004, 279, 32035-32045.

18. J. J. Reina, S. Sattin, D. Invernizzi, S. Mari, L. Martinez-Prats, G. Tabarani, F. Fieschi, R. Delgado, P. M. Nieto, J. Rojo and A. Bernardi, ChemMedChem, 2007, 2, 1030-1036.

19. M. J. Borrok and L. L. Kiessling, J. Am. Chem. Soc., 2007, 129, 12780-12785.

20. S. Sattin, A. Daghetti, M. Thepaut, A. Berzi, M. Sanchez-Navarro, G. Tabarani, J. Rojo, F. Fieschi, M. Clerici and A. Bernardi, ACS Chem. Biol., 2010, 5, 301-312.

21. C. Guzzi, J. Angulo, F. Doro, J. J. Reina, M. Thepaut, F. Fieschi, A. Bernardi, J. Rojo and P. M. Nieto, Org. Biomol. Chem., 2011, 9, 7705-7712.

22. N. Obermajer, S. Sattin, C. Colombo, M. Bruno, U. Svajger, M. Anderluh and A. Bernardi, Mol. Divers., 2011, 15, 347-360.

23. N. Varga, I. Sutkeviciute, C. Guzzi, J. McGeagh, I. Petit-Haertlein, S. Gugliotta, J. Weiser, J. Angulo, F. Fieschi and A. Bernardi, Chem. Eur. J., 2013, 19, 4786-4797.

24. M. Thepaut, C. Guzzi, I. Sutkeviciute, S. Sattin, R. Ribeiro-Viana, N. Varga, E. Chabrol, J. Rojo, A. Bernardi, J. Angulo, P. M. Nieto and F. Fieschi, J. Am. Chem. Soc., 2013, 135, 2518-2529.

25. I. Sutkeviciute, M. Thépaut, S. Sattin, A. Berzi, J. McGeagh, S. Grudinin, J. Weiser, A. Le Roy, J. J. Reina, J. Rojo, M. Clerici, A. Bernardi, C. Ebel and F. Fieschi, ACS Chem. Biol., 2014, 9, 13771385.

26. H. Feinberg, D. A. Mitchell, K. Drickamer and W. I. Weis, Science, 2001, 294, 2163-2166.
27. Y. Guo, H. Feinberg, E. Conroy, D. A. Mitchell, R. Alvarez, O. Blixt, M. E. Taylor, W. I. Weis and K. Drickamer, Nat. Struct. Mol. Biol., 2004, 11, 591-598.

28. H. Feinberg, Y. Guo, E. Conroy, D. Mitchell, R. Alvarez, O. Blixt, M. Taylor, K. Drickamer and W. Weis, Glycobiology, 2005, 15, 1195-1195.

29. H. Feinberg, R. Castelli, K. Drickamer, P. H. Seeberger and W. I. Weis, J. Biol. Chem., 2007, 282, 4202-4209.

30. J. J. Reina, I. Diaz, P. M. Nieto, N. E. Campillo, J. A. Paez, G. Tabarani, F. Fieschi and J. Rojo, Org. Biomol. Chem., 2008, 6, 2743-2754.

31. J. Angulo, I. Diaz, J. J. Reina, G. Tabarani, F. Fieschi, J. Rojo and P. M. Nieto, ChemBioChem, 2008, 9, 2225-2227.

32. G. Timpano, G. Tabarani, M. Anderluh, D. Invernizzi, F. Vasile, D. Potenza, P. M. Nieto, J. Rojo, F. Fieschi and A. Bernardi, ChemBioChem, 2008, 9, 1921-1930.

33. J. Angulo and P. M. Nieto, Eur. Biophys. J., 2011, 40, 1357-1369.

34. D. Doknic, M. Abramo, I. Sutkeviciute, A. Reinhardt, C. Guzzi, M. K. Schlegel, D. Potenza, P. M. Nieto, F. Fieschi, P. H. Seeberger and A. Bernardi, Eur. J. Org. Chem., 2013, 2013, 5303-5314.

35. C. Guzzi, J. C. Muñoz-García, P. M. Enriquez-Navas, J. Rojo, J. Angulo and P. M. Nieto, Pure Appl. Chem., 2013.

36. P. M. Enríquez-Navas, C. Guzzi, J. C. Muñoz-García, P. M. Nieto and J. Angulo, in Methods Mol. Biol., 2015, vol. 1273, pp. 475487.

37. J. Angulo, P. M. Enriquez-Navas and P. M. Nieto, Chem. Eur. J., 2010, 16, 7803-7812.

38. P. M. Enriquez-Navas, C. Guzzi, J. C. Muñoz-Garcia, P. M. Nieto and J. Angulo, in Glycoinformatics, eds. T. Lütteke and $M$. Franck, Humana Press, 2015.

39. K. Pederson, D. A. Mitchell and J. H. Prestegard, Biochemistry, 2014, 53, 5700-5709.

40. J. J. Reina, O. S. Maldonado, G. Tabarani, F. Fieschi and J. Rojo, Bioconj. Chem., 2007, 18, 963-969.

41. M. Mayer and B. Meyer, Angew. Chem. Int. Ed., 1999, 38, 17841788.

42. J. Jeener, B. H. Meier, P. Bachmann and R. R. Ernst, J. Chem. Phys., 1979, 71, 4546-4553.

43. V. Jayalakshmi and N. R. Krishna, J. Magn. Reson., 2002, 155, 106-118.

44. S. Mari, I. Sanchez-Medina, P. Mereghetti, L. Belvisi, J. JimenezBarbero and A. Bernardi, Carbohydr. Res., 2007, 342, 18591868.

45. J. Jeener, B. H. Meier, P. Bachmann and R. R. Ernst, J. Chem. Phys., 1979, 71, 4546-4553.

46. M. Mayer and B. Meyer, J. Am. Chem. Soc., 2001, 123, 61086117.

47. N. R. Krishna, D. G. Agresti, J. D. Glickson and R. Walter, Biophys. J., 1978, 24, 791-814.

48. Y. Xu, I. P. Sugar and N. R. Krishna, J. Biomol. NMR, 1995, 5, 3748.

49. The transfer NOE relies on the difference between the correlation times of the free ligand and the ligand when bound to the receptor. Ideally the small and faster moving free ligand shows a weak, slow growing positive NOE, while the complexed ligand should obtain the motional properties from the large and slow receptor leading to strong, negative and fast growing NOE. As in transfer NOE the averaged NOE is observed, the predominant NOE should correspond to the large molecule, and is observed via the averaged signals of the ligand. Flexibles molecules can be described using the Lipari-Szabo formalism where the order parameter and internal motions modify the 
influence of the global correlation time on relaxation properties. Consequently, regions of a molecule with larger flexibility show smaller relaxation parameters than those inferred by the global correlation time for the rigid zones and therefore smaller relaxation rates and NOE. Thus, as the 1-6 linkages have larger flexibility, faster internal motions and smaller order parameters, and hence reduced NOE values, the observed averaged transfer NOE peaks might be underestimated.

50. A. Kumar, R. R. Ernst and K. Wüthrich, Biochem. Biophys. Res. Commun., 1980, 95, 1-6.

51. F. Ni, Prog. Nucl. Magn. Reson. Spectrosc., 1994, 26, 517-606.

52. Spin diffusion was previously observed for the binding of the pseudomannobioside to DC-SIGN. In the present work, a sign of the presence of spin diffusion is the observation of the intraresidual cross peak $\mathrm{H} 3-\mathrm{M} / \mathrm{H} 1-\mathrm{M}$, corresponding to a fixed intraring distance, in the trNOESY spectrum, which is not observed in free state (NOESY). Besides, other inter-residual NOEs (H3$\mathrm{M} / \mathrm{H}$ eeq-C) visible only in the presence of DC-SIGN (ECD) also involve the proton $\mathrm{H} 3$ of the non-reducing mannose. Significantly, this proton is very close to the protein surface as shown in the X-ray structure and observed in solution by its strong STD signal. This supports the protein-mediated spin diffusion pathway through this proton as the origin of these cross peaks

53. R. Wagner and S. Berger, J. Magn. Reson. A, 1996, 123, 119-121.

54. M. Mayer and T. L. James, J. Am. Chem. Soc., 2004, 126, 44534460.

55. S. Neal, A. M. Nip, H. Zhang and D. S. Wishart, J. Biomol. NMR, 2003, 26, 215-240.

56. v. Schrödinger Release 2013-2: Maestro, Schrödinger, LLC, New York, NY, 2013., Journal, 2013.

57. J. L. Banks, H. S. Beard, Y. Cao, A. E. Cho, W. Damm, R. Farid, A. K. Felts, T. A. Halgren, D. T. Mainz, J. R. Maple, R. Murphy, D. M. Philipp, M. P. Repasky, L. Y. Zhang, B. J. Berne, R. A. Friesner, E. Gallicchio and R. M. Levy, J. Comput. Chem., 2005, 26, 17521780.

58. W. C. Still, A. Tempczyk, R. C. Hawley and T. Hendrickson, J. Am. Chem. Soc., 1990, 112, 6127-6129.

59. J. Weiser, P. S. Shenkin and W. C. Still, J. Comput. Chem., 1999, 20, 217-230.

60. I. Kolossváry and W. C. Guida, J. Am. Chem. Soc., 1996, 118, 5011-5019.

61. J. Luczkowiak, S. Sattin, I. Sutkeviciute, J. Juan Reina, M. Sanchez-Navarro, M. Thepaut, L. Martinez-Prats, A. Daghetti, F. Fieschi, R. Delgado, A. Bernardi and J. Rojo, Bioconj. Chem., 2011, 22, 1354-1365.

62. T. K. Dam and C. F. Brewer, Glycobiology, 2010, 20, 270-279. 
RSC Author Templates - ChemDraw (CDX) - Graphical Abstracts

All text and images must be placed within the frame.

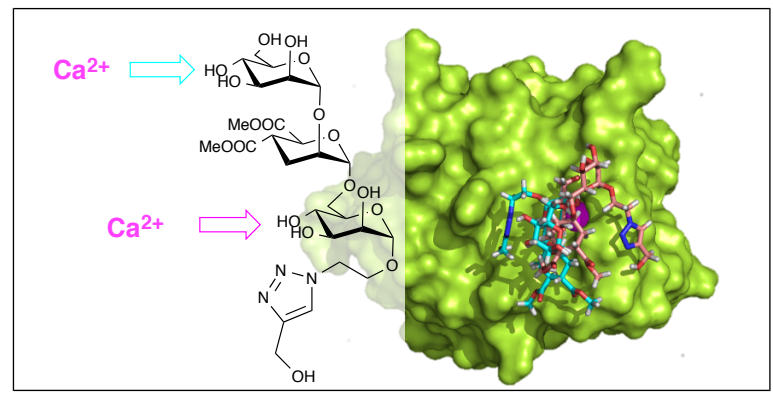




\section{Detection and Quantitative Analysis of Two Independent Binding Modes of a Small Ligand Responsible for DC-SIGN Clustering.}

Cinzia Guzzi, ${ }^{[a]}$ Pietro Alfarano, ${ }^{[b]}$ leva Sutkeviciute, ${ }^{[c, d, e]}$ Sara Sattin,${ }^{[f]}$ Renato RibeiroViana ${ }^{[a]}$ Franck Fieschi, ${ }^{[c, d, ~ e]}$ Anna Bernardi, ${ }^{[f]}$ Jörg Weiser, ${ }^{[b]}$ Javier Rojo, ${ }^{[a]}$ Jesús Angulo, ${ }^{[[a, g]}$ and Pedro M. Nieto, ${ }^{[a]}$

Electronic Supplementary Material

a. Glycosystems Laboratory. Instituto de Investigaciones Químicas (IIQ) / cicCartuja. CSIC / US, Americo Vespucio, 49, 41092 Sevilla, (Spain).

E-mail: pedro.nieto@iiq.csic.es

$b$. 20126, Milan (Italy).

c. Anterio Consult\&Research GmbH, Augustaanlage 2368165 Mannheim (Germany).

d. Univ. Grenoble Alpes, Institut de Biologie Structurale (IBS), F-38044 Grenoble, (France)

e. $\quad$ CNRS, IBS, F-38044 Grenoble, (France)

f. $\quad$ CEA, IBS, F-38044 Grenoble, (France)

g. Dipartimento di Chimica, Universita' degli Studi di Milano, via Golgi 19, 20133 Milano, (Italy)

h. School of Pharmacy, University of East Anglia, Norwich Research Park, Norwich, NR4 7TJ, (UK). E-mail: j.angulo@uea.ac.uk 


\section{Conformational analysis of $\mathbf{2} \omega$ torsional angle.}

All the potential conformers of $\mathbf{2}^{1}$ were constructed and minimised using Maestro 10.0 from Schrodinger and qualitatively analysed considering the interprotonic NOE for the atoms defining the dihedrals Phi, Psi and omega obtained from the transfer NOESY experiments. Only four or them were compatible with the transfer NOESY results: A (phi 180, omega 60) B (phi 180, omega -60) C (phi 90, omega 60) and D (phi 90, omega -60) Figure S1. Their STD were calculated and none of them alone was able to explain de experimental STD values. Additionally, none of the potential combinations of conformers could explain the experimental STD pattern.

Simulation parameters for CORCEMA ST: solvent $\mathrm{D}_{2} \mathrm{O} ; \tau_{\mathrm{c}}$ (ligand) 0.5 ns; $\tau_{\mathrm{c}}$ (protein) $115 \mathrm{~ns} ; \tau_{\mathrm{c}}$ (ligand) $0.5 \mathrm{~ns}$; Order parameter $\left(\mathrm{S}^{2}\right) 0.85 ; \tau_{\mathrm{i}} 0.01 \mathrm{~ns}$; ligand concentration $1 \mathrm{mM}$; Protein concentration $19 \mathrm{uM} ; \mathrm{B}_{0} 500 \mathrm{MHz} ; \rho_{0} 0.1 \mathrm{~s}^{-}$ 1; $\mathrm{K}_{\mathrm{D}} 0.4 \mathrm{mM}$; $\mathrm{k}_{\text {on }} 1.00 \mathrm{E}+08$. Chemical shifts for protons were calculated from ShiftX (http://shiftx.wishardtlab.com/). Irradiation frequency was set to $0.00 \mathrm{ppm}$ and protons were considered instantly saturated within a range of $0.7 \mathrm{ppm}$.

Figure S1-S4. Complexes A, B, C, D. Three dimensional structure of the binding site with the ligand (top) and calculated STD growing curves (bottom)

\footnotetext{
${ }^{1}$ Except $\Phi$ conformers, assuming the prevalence of the exo-anomeric effect.
} 

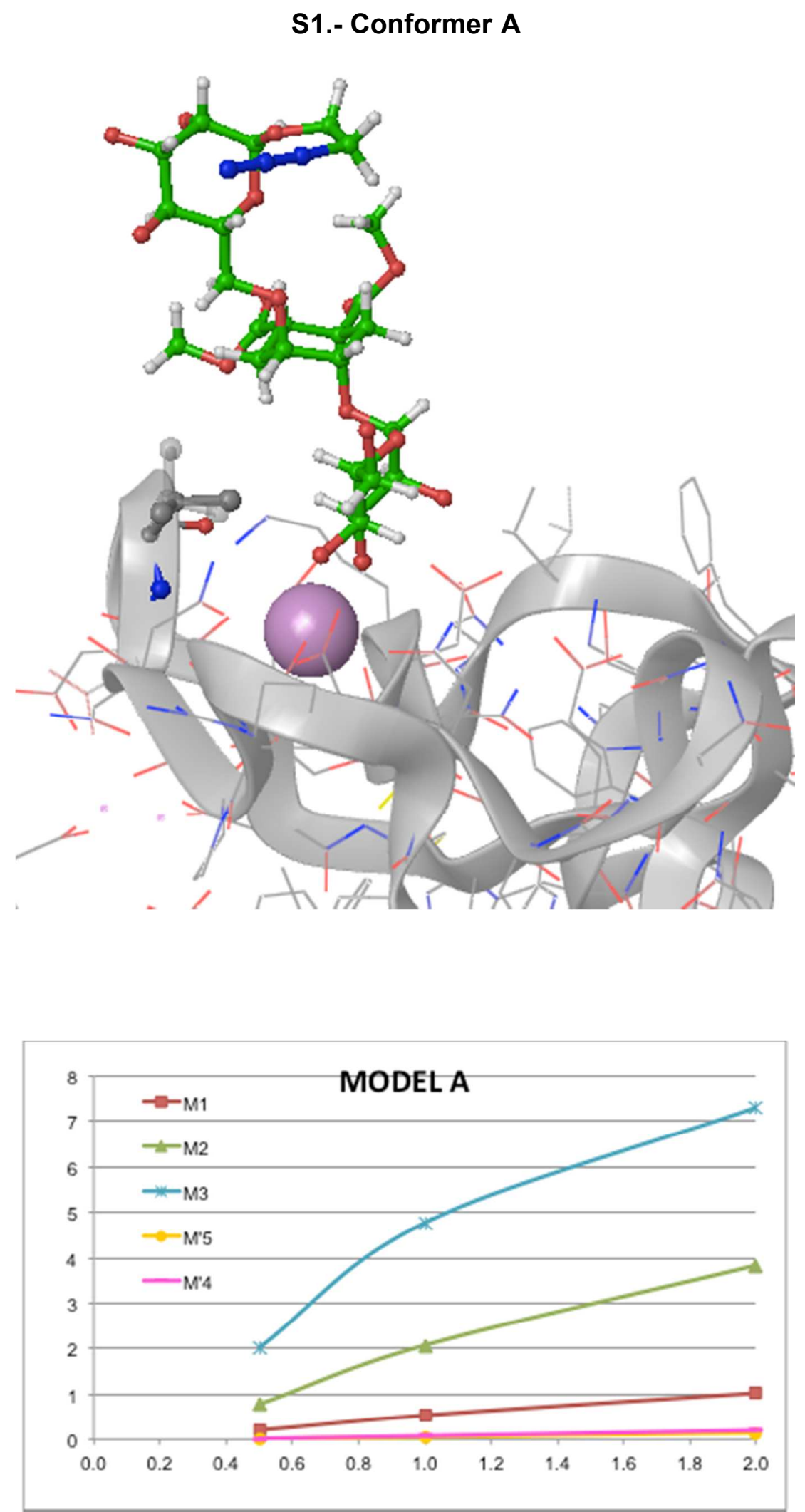


\section{S2.- Conformer B}
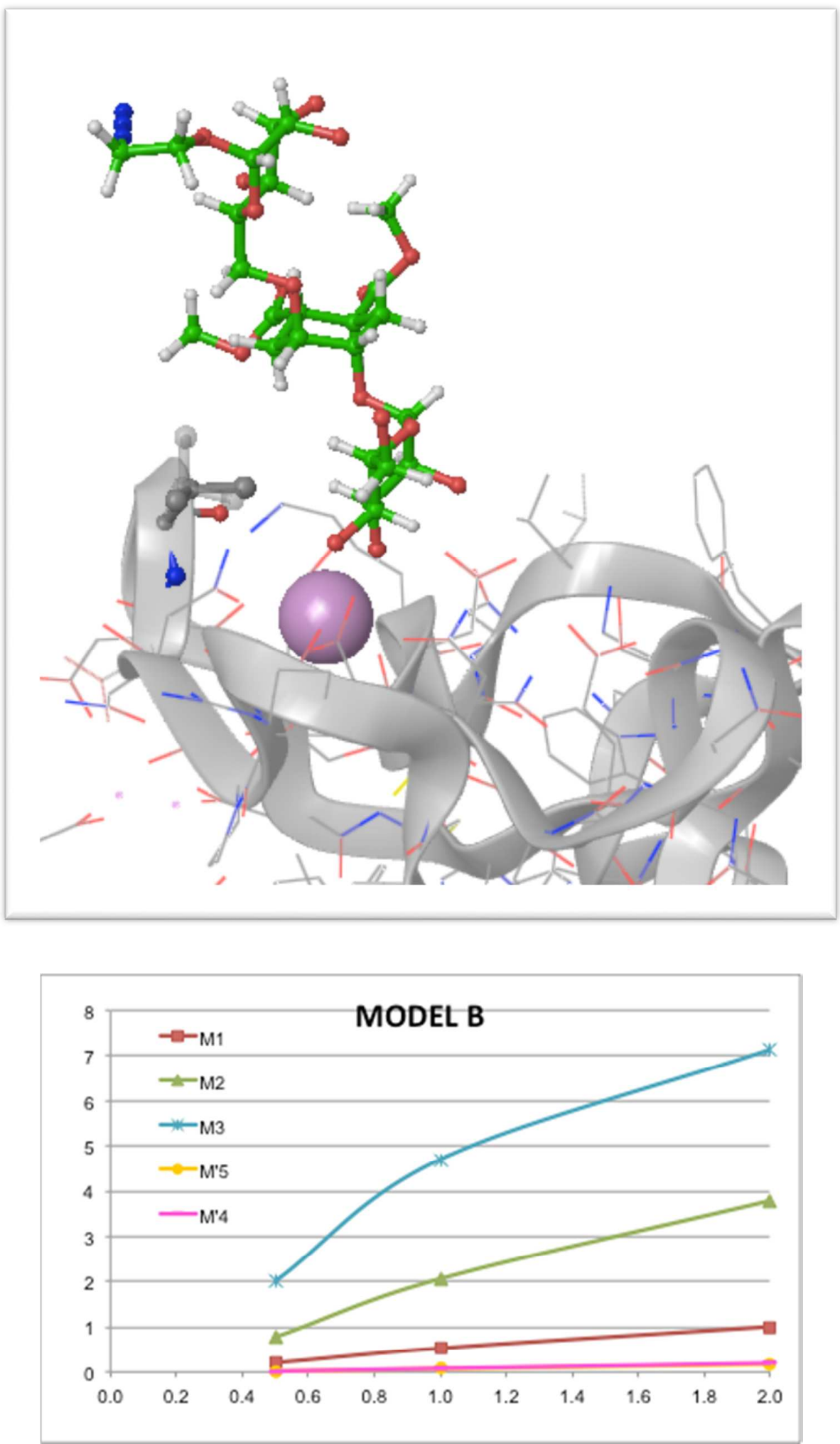


\section{S3.-Conformer C}
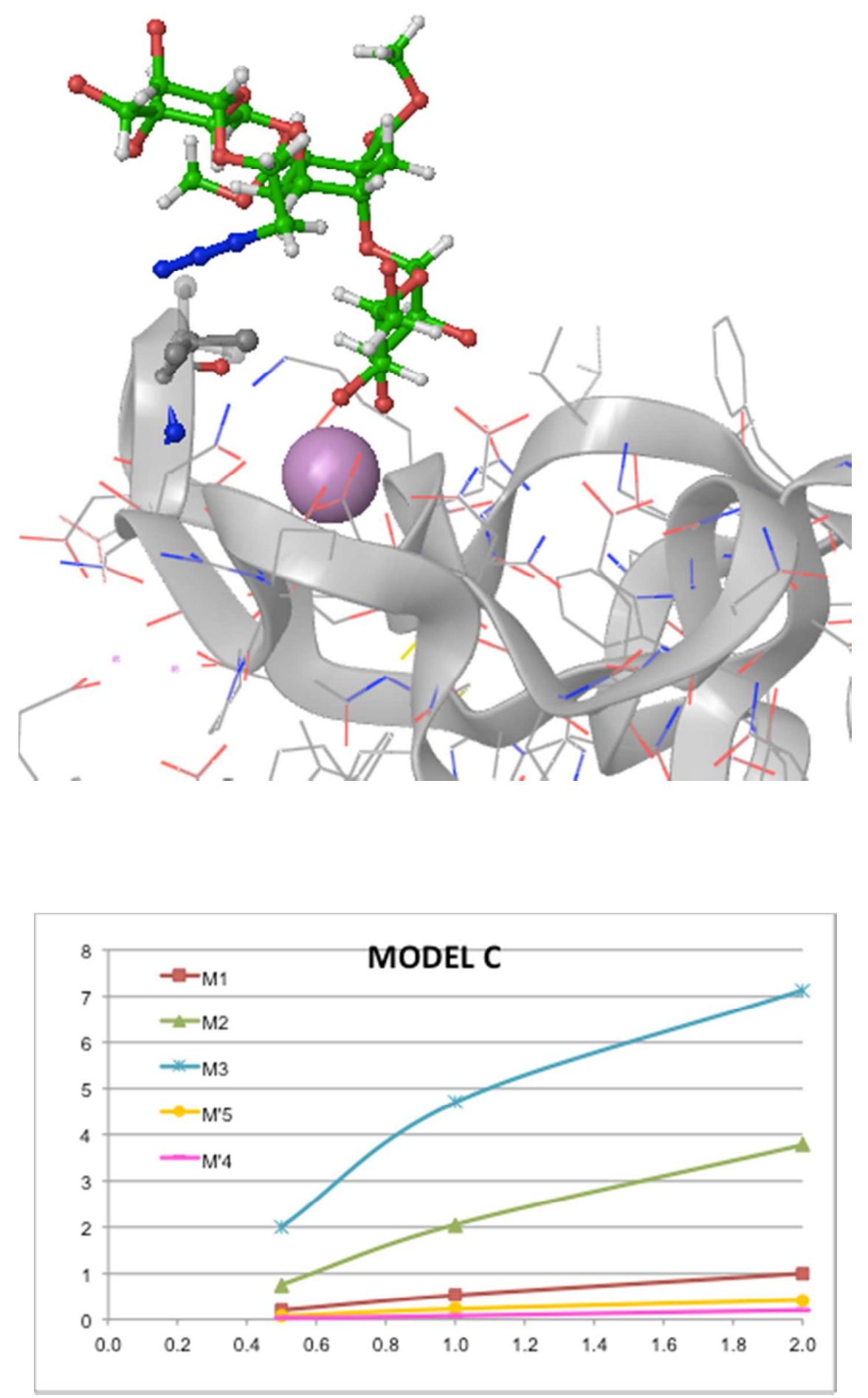
$\cdot D$

S4.- Conformer D
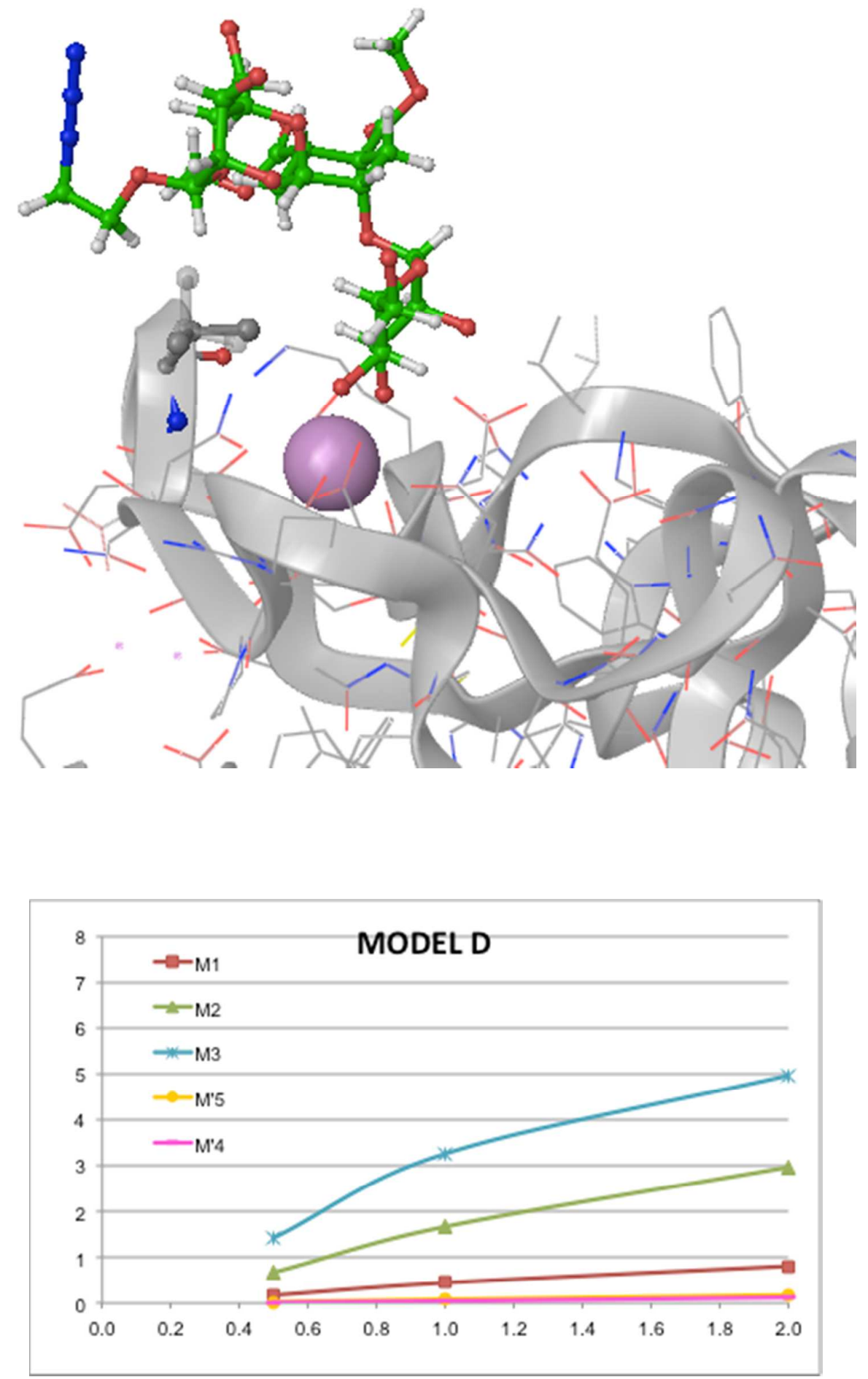
Table S1. 2 STD values, and overlapping description.

\begin{tabular}{|c|c|c|c|}
\hline & STD 2s & Overlaped with & Observations \\
\hline M' H1 & 1.43 & & \\
\hline$M^{\prime} \mathrm{H} 2$ & 3.16 & & \\
\hline M' H3 & 4.54 & & \\
\hline $\mathrm{M}^{\prime} \mathrm{H} 4$ & & M H6 M H3 M' H5 & \\
\hline M' H5 & & M H6 M H3 M' H4 & \\
\hline $\begin{array}{l}\text { M' H6, } \\
\text { M' H6, }\end{array}$ & & $\begin{array}{l}\text { M H2 } \\
\text { M H2' }\end{array}$ & \\
\hline \multicolumn{4}{|l|}{ C H1 } \\
\hline \multicolumn{4}{|l|}{$\mathrm{C} \mathrm{H} 2$} \\
\hline C H3ax & & C 6ax & \\
\hline C H3eq & & C 6eq & \\
\hline $\mathrm{C} \mathrm{H} 4$ & & $\mathrm{CH} 5$ & \\
\hline C H5 & & $\mathrm{C} \mathrm{H} 4$ & \\
\hline C H6ax & & C 3ax & \\
\hline C H6eq & & C 3eq & \\
\hline M H1 & & & Water suppresed \\
\hline M H2 & & M H6 & \\
\hline M H3 & & $M^{\prime} 4,5$ and $M 6$ & \\
\hline M H4 & 2.0 & & \\
\hline M H5 & 1.4 & & \\
\hline M H6,H6' & & H3 H4' H5 & \\
\hline T H1 & 0.62 & & \\
\hline $\mathrm{T} \mathrm{CH} 2 \mathrm{O}$ & & & Water suppresed \\
\hline T CH2N & & & Water suppresed \\
\hline $\mathrm{T} \mathrm{CH} 2 \mathrm{OH}$ & 0.0 & & Clean region \\
\hline OCH3 & 1.83 & & \\
\hline
\end{tabular}

